\title{
PORTUGUESES FACE A ESPANHÓIS, AMERICANOS E CABO- -VERDIANOS, EM PORTUGAL: DISTÂNCIA SOCIAL, ESTEREÓTIPOS E PREDISPOSIÇÃO PARA A MUDANÇA ATITUDINAL
}

\author{
Joana Miranda
}

Resumo: O artigo apresenta resultados de um estudo sobre a identidade nacional e as representações de alguns exogrupos em Portugal - distância social, estereótipos e predisposição para a mudança atitudinal. Os 446 estudantes de nacionalidade portuguesa que participaram no estudo - 241 do ensino secundário, 205 do ensino superior, 194 raparigas e 252 rapazes - tinham idades compreendidas entre os $14 \mathrm{e}$ os 36 anos. O instrumento utilizado foi um questionário com diferentes versões consoante o exogrupo de comparação considerado: Espanhóis, Americanos ou Cabo-Verdianos. Com base nos resultados, foi introduzido o conceito de assimetria variada nas relações intergrupais, conceito que pretende traduzir a ideia de que o mesmo grupo pode assumir uma posição de dominante, num dado contexto de comparação, e a de dominado, num outro contexto.

Palavras chave: Grupos nacionais, distância social, estereótipos, mudança atitudinal.

Portuguese towards Spaniards, Americans and Cape-Verdians in Portugal: social distance, stereotypes and predisposition to attitudinal change (Abstract): The article presents results of a study concerning national identity and the representations of some exogroups in Portugal - social distance, stereotypes and predisposition to attitudinal change. The 446 Portuguese students who participated in the study 241 from high school, 205 from college, 194 female and 252 male - were aged from fourteen to thirty-six. The instrument used was a questionnaire with seven versions, according to the comparison exogroups: Spaniards, Americans or Cape-Verdians. Considering the results, the concept of varied asymmetry was introduced, and this concept pretends to express the idea that the same group may assume the dominant position in a certain comparison context and that of the dominated position in another different one.

Keywords: National groups, social distance, stereotypes, attitudinal change.

\footnotetext{
${ }^{1}$ Psicóloga. Professora Auxiliar da Universidade Aberta. Investigadora do Centro de Estudos das Migrações e das Relações Interculturais (CEMRI). Email: joana@univ-ab.pt.
} 
$\mathrm{O}$ artigo tem por base a investigação de doutoramento da autora, intitulada $A$ identidade nacional. Do mito ao sentido estratégico. Uma análise psicossociológica da comparação entre os Portugueses e os Outros ${ }^{2} \mathrm{O}$ artigo procura contextualizar a investigação de doutoramento e apresentar, de entre os diversos resultados obtidos, apenas os que concernem à variável independente exogrupo de comparação: espanhóis, americanos e cabo-verdianos e as variáveis dependentes distância social, estereótipos e predisposição para a mudança atitudinal.

A investigação insere-se num quadro de mudanças estruturais recentes que têm tido lugar na sociedade portuguesa. De facto, a passagem de Portugal de país predominantemente de emigrantes a país predominantemente de imigrantes quebrou a aparente homogeneidade de um território linguístico, religioso e simbólico, cujo isolamento económico e político fora já ultrapassado com a entrada, em 1986, do país na CEE. Os estrangeiros passaram a ocupar um lugar cativo nos meios de comunicação social, foram sendo perspectivados comparativamente aos portugueses, seja através do confronto de culturas e de condições sociais, seja por razões mais lamentáveis, como sejam o crime e a violência ${ }^{3}$. O objecto de estudo inscreve-se, assim, num quadro de emergência da consciência dos fenómenos de intolerância e de racismo na opinião pública e de desenvolvimento do conhecimento sobre essa problemática, no meio académico.

Portugal é por nós conceptualizado como "país intermédio", o que, de acordo com autores como Telo (1997, p. 652), constitui o elemento estruturante básico da identidade colectiva dos portugueses. Fomos o único país colonizador a ser considerado por outros países colonizadores como um país nativo ou selvagem. Santos (1994) considera que a nossa realidade é a de um país numa situação de intermediário, decorrente de uma posição intermédia em termos de desenvolvimento, no seio da conjuntura mundial (Santos, 1994), e que, apesar de o país estar integrado numa comunidade de países europeus a que muitos países aspirariam pertencer, o facto é que continua a ser o receptáculo de países mais poderosos, de entre os quais se destacam os Estados Unidos da América. O autor acrescenta que, em Abril de 1974, Portugal era o país menos desenvolvido da Europa e, simultaneamente, o único detentor do maior e mais duradouro império colonial europeu (Santos, 1994: 58).

\footnotetext{
2 Para uma compreensão mais aprofundada da investigação, recomenda-se a consulta de Miranda, J. (2002). Identidade nacional. Do mito ao sentido estratégico. Uma análise psicossociológica das comparações entre os Portugueses e os Outros. Oeiras: Celta.

${ }^{3}$ A perpectivação dos estrangeiros pelos meios de comunicação social envolve considerável subjectividade. Sobre esta questão, é particularmente elucidativa a obra de van Dijk, T. (1987). Communicating racism. Ethnic prejudice in thought and talk. Londres: Sage.
} 
É com base na consideração de Portugal como país intermédio que construímos uma situação empírica em que Portugal assume, simultaneamente, a posição de dominante, de dominado e de "igual".

De acordo com a hipótese geral que norteou a investigação, a identidade social não representaria uma criação do próprio grupo, inscrevendo-se, antes, numa dinâmica intergrupal (na relação entre os portugueses e os outros grupos), de ordem psicossociológica. O ser português constituiria um processo de construção, desempenhando os demais alvos de comparação (grupos nacionais) um papel determinante na construção da identidade nacional. Em articulação com esta hipótese geral, temos a seguinte hipótese específica: Hipótese 1: Se os americanos constituem um grupo de referência positiva e os cabo-verdianos um grupo de referência negativa, espera-se que haja maior diferenciação em relação aos cabo-verdianos do que em relação aos americanos, podendo os espanhóis ocupar uma posição central.

No plano teórico, a investigação situa-se no âmbito das identidades sociais enquanto representações sociais, mais precisamente, as representações dos outros e de nós. Apesar de a fundamentação teórica estar inscrita no campo da Psicologia Social, não foi negligenciada a análise do contexto histórico e sociológico, fundamentais para a compreensão do tipo de fenómenos em causa ${ }^{4}$.

\section{Fundamentação teórica}

Uma das principais teorias subjacentes à elaboração do nosso estudo foi a teoria da identidade social (TIS) de Tajfel, apoiada em três processos sociais fundamentais, cuja conceptualização foi desenvolvida pelo autor de forma articulada: categorização social, identidade social e comparação social. Fundamental na TIS é a ideia de que identidades positivas e negativas têm diferentes implicações, a nível do comportamento intergrupal, e de que, assim sendo, a identidade social constituiria uma variável de background do comportamento intergrupal ou, de outro modo, um mecanismo causal em situações de mudança social. Assim, a identidade social poderá ser positiva ou negativa, consoante a pertença a um dado grupo contribua ou não, de forma satisfatória, para o auto-conceito do indivíduo. Outra ideia basilar é a de que a procura de um conceito ou imagem satisfatória de si mesmos se processa mediante o processo de comparação social e de que, para que tal comparação contribua positivamente para a auto-estima, é

\footnotetext{
${ }^{4}$ Neste artigo, não se procede a qualquer contextualização de natureza histórica ou sociológica.
} 
necessário que o outro grupo seja perspectivado como potencialmente similar ou comparável ao próprio. A percepção da ilegitimidade, em termos de diferenças em estatuto, poder ou qualquer outra característica, implicaria o desenvolvimento de algumas dimensões de comparabilidade (similaridades subjacentes). Os indivíduos e os grupos seriam capazes de descobrir e de criar dimensões de comparação úteis à sua identidade.

Uma teoria também relevante para o background teórico do estudo é a teoria da auto-categorização de Turner (1985; Turner et al., 1987; Turner \& Oakes, 1989), segundo a qual a identidade social e a identidade pessoal não constituem formas qualitativamente diferentes de identidade, mas antes formas diferentes de auto-categorização. Esta teoria constitui um desenvolvimento da teoria da identidade social de Tajfel, desenvolvendo o constructo de identidade e o processo de categorização, reconceptualizando a relação entre identidade pessoal e social e sugerindo um mecanismo que permitiria predizer quando e como os indivíduos se auto-categorizam de uma forma ou de outra. Enquanto que a teoria da identidade social era essencialmente motivacional, esta teoria é essencialmente cognitiva. Outra abordagem relevante para o nosso estudo é a que a Escola de Genève faz da identidade social, articulando diferentes níveis de análise, para além do nível estritamente psicológico considerado pelos seguidores da Escola de Bristol. Esta corrente de investigação critica a Escola de Bristol, pelo facto de, da ligação entre os processos de categorização social, identidade social e comparação social, não ter resultado uma verdadeira articulação entre níveis de análise (Doise, 1982, 1984). E não resultou, uma vez que houve décalage entre um modelo teórico que integrava dimensões explicativas sociológicas e psicológicas numa rede de causalidade complexa, e o seu suporte empírico, em que não se procedeu a tal articulação (Doise, 1987). De acordo com a escola, foi uma variável de ordem aparentemente psicológica: a identidade social que, intimamente dependente de um dado paradigma experimental, passou a assumir uma função causal determinante. Esta linha de pensamento considera que, apenas num quadro em que os diferentes níveis de análise sejam integrados, poderá a identidade ser entendida enquanto um processo de significância ou de construção social da realidade das relações intergrupais, processo esse que se exprime em modalidades mais individualizantes ou mais homogeneizantes, consoante as posições objectivas dos grupos (Amâncio, 1994).

Uma das primeiras contribuições da Escola de Genève foi o modelo da diferenciação categorial formulado por Doise $(1976,1984)$ no início dos anos setenta. Este modelo é fundamental quando considera que os indivíduos "constroem" uma representação ou manifestam comportamentos que 
traduzem uma estrutura cognitiva "reprodutora" do contexto em que estão inseridos e que as representações constituem justificações do próprio comportamento.

Codol (1984) revela-se um autor fundamental, ao considerar que o comportamento do indivíduo no seio do grupo e em relação ao(s) grupo(s) relevante(s) não é universalmente orientado por uma motivação, mas sim pela referência a valores e normas colectivas que a categorização intergrupal torna significativas ou a normas contextuais que possibilitam a procura da singularidade, quer através da diferença, quer através da semelhança. Assim, Codol chama a atenção para o facto de a diferenciação ser contextual, isto é, dependente das normas do contexto (Codol, 1984).

Uma das referências colectivas que Codol considera são as ideologias relativas à estratificação dos grupos sociais, numa escala de poder. Um outro autor da escola - Deschamps (1982) - designa essa escala de poder de "universo simbólico comum de valores", o qual serve de referência ao posicionamento relativo de todos os grupos e, portanto, à sua interdependência comparativa. Central é, ainda, o conceito de Taboada-Leonetti (1990), de estratégias identitárias, resultado de elaboração individual/colectiva dos actores, variando em função das situações e dos contextos e consequência dos objectivos dos mesmos (1990). Entre as finalidades das estratégias, estão a diferenciação (1990) e a valorização (1990). Um outro conceito considerado é o de inconsistência de estatuto de um grupo de Maleswka-Peyre (1990), que se refere ao facto de um mesmo grupo poder ser dominante num contexto e dominado num outro contexto.

A teorização sobre representações constitui um pano de fundo subjacente a toda a nossa conceptualização. A teoria das representações sociais de Moscovici procurou reintroduzir uma abordagem mais social na Psicologia Social, enfatizando conceitos colectivos como os de cultura e ideologia. A premissa-base é a de que o indivíduo é, antes do mais, um ser social cuja existência e identidade estão enraizados numa colectividade. $\mathrm{O}$ indivíduo mantém uma relação dialéctica com a sociedade, é produto dela (das suas normas, convenções e valores) e, simultaneamente, um participante activo que a pode transformar (Augoustinos \& Walker, 1995).

Billig (1993) salientou a importância do estudo das representações sociais para a compreensão da sociedade pensante ("the thinking society"), sendo ainda hoje problemática a questão da sua avaliação (Breakwell \& Canter, 1993). As representações resultariam de interacção social e construiriam a compreensão do mundo social, permitindo a interacção entre grupos que partilham a representação (Augoustinos \& Walker, 1995). 


\section{Método}

\section{População}

Como pode ser observado no quadro 1, participaram neste estudo 446 estudantes de nacionalidade portuguesa, de ambos os sexos, sendo 241 do ensino secundário (10. ${ }^{\circ}$ ano, na Escola Secundária de Odivelas) e 205 do ensino superior ( $4 .^{\circ}$ e $5 .^{\circ}$ anos da Licenciatura em Engenharia Civil do Instituto Superior Técnico de Lisboa), 194 raparigas e 252 rapazes. Não sendo o estudo suportado por uma amostra representativa, não foi nosso objectivo generalizar os resultados e conclusões à população jovem nacional, mas antes aprofundar os processos psicossociológicos que estão na base do olhar dos portugueses sobre outros grupos nacionais e sobre si mesmos, em contextos estimulantes da comparabilidade social.

Quadro 1 - Distribuição dos participantes por sexo, grau de ensino, exogrupo de comparação e ordem de apresentação

\begin{tabular}{lccccc}
\hline $\begin{array}{l}\text { Exogrupo de compa- } \\
\text { ração e ordem de } \\
\text { apresentação }\end{array}$ & \multicolumn{2}{c}{ Masculino } & \multicolumn{2}{c}{ Feminino } & Total \\
\cline { 2 - 4 } Espanhóis & Secundário & Superior & Secundário & Superior & \\
A & 18 & 15 & 14 & 11 & 58 \\
B & 18 & 17 & 12 & 8 & 55 \\
\hline Americanos & 18 & 16 & 17 & 10 & 61 \\
A & 16 & 15 & 12 & 11 & 54 \\
B & 19 & 13 & 14 & 13 & 59 \\
\hline Cabo-Verdianos & 15 & 14 & 11 & 12 & 52 \\
A & 29 & 29 & 28 & 21 & 107 \\
B & 133 & 119 & 108 & 86 & 446 \\
\hline Sem exogrupo & & & & & \\
\hline Total & & & & & \\
\hline
\end{tabular}




\section{Idades}

A média de idades da população do secundário era de $15,73^{5}$ (desvio-padrão $=0,94)$, situando-se os valores extremos em 14 e 20 anos. A média de idades da população do superior era de 23,25 (sendo o desvio-padrão de 2,12 ), situando-se os valores extremos em 21 e 36 anos. As diferenças entre as médias de idades dos dois grupos são significativas $(t(444)=-49,50$, $\mathrm{p}<0,01)$.

\section{Habilitações escolares dos progenitores}

O nível de habilitações médias dos progenitores situou-se próximo do valor 5, correspondente, na nossa escala, ao 9. ${ }^{\circ}$ ano ou equivalente. Encontraram-se diferenças entre os níveis de habilitações dos pais dos participantes do secundário $(4,74)$ e do superior $(5,81) \quad(t(444)=-5,76$, $p<0,01)$, entre o nível de habilitações das mães do secundário $(4,60)$ e do superior $(5,38) \quad(t(444)=-4,15, p<0,01)$ e entre o nível médio de habilitações dos prógenitores do secundário $(4,68)$ e do superior $(5,59)$ $(t(444)=-5,24, p<0,01)$. As diferenças indicam que os progenitores dos estudantes do superior possuíam níveis de habilitações significativamente mais altas do que os do secundário.

\section{Paises de origem dos participantes}

De entre os 446 participantes, 413 nasceram em Portugal, sendo, portanto, muito poucos os que nasceram no estrangeiro. De entre os países de origem dos participantes que não nasceram em Portugal, destacam-se Angola (11), França (6) e Moçambique (4).

\section{Países de origem dos pais}

De entre os 892 progenitores, 827 nasceram em Portugal, sendo, pois, muito poucos os que nasceram no estrangeiro. De entre os países de origem dos progenitores que não nasceram em Portugal, destaca-se Angola (32), Moçambique (15) e Cabo Verde (8).

\footnotetext{
5 Todos os valores apresentados foram alvo de arredondamento às centésimas.
} 


\section{Desenho experimental e razões de escolha dos exogrupos}

A variável independente exogrupo de comparação tem três níveis, consoante o alvo de comparação sejam os espanhóis, os americanos ou os cabo-verdianos ${ }^{6}$.

Uma das primeiras preocupações no delinear da investigação foi, decerto, a escolha dos exogrupos. A escolha dos espanhóis, dos americanos e dos cabo-verdianos como grupos em relação aos quais se analisa o olhar dos portugueses, prende-se com o facto de considerarmos que a escolha conjunta destes grupos permite construir uma situação experimental de assimetria simbólica, em que Portugal assume simultaneamente a posição de dominante (em relação a Cabo Verde), de dominado (em relação aos Estados Unidos) e de ambivalência (em relação a Espanha) ${ }^{7}$ ou, de outra forma, uma situação em que a identidade social dos participantes é confrontada com outras que evocam relações intergrupais de assimetria variada. Para além desta razão determinante da escolha dos grupos nacionais em causa, qualquer um dos três se encontrava, ao tempo do estudo, entre os dez países do mundo com maior número de população residente em Portugal.

\section{O instrumento de medida}

O questionário foi construído de modo a integrar quatro grandes conjuntos de indicadores (blocos) considerados relevantes para a investigação.

O primeiro conjunto de itens (bloco de caracterização), teve por objectivo recolher dados pessoais dos participantes. Incluía itens relativos ao sexo, grau de ensino, idade, nível de habilitações dos pais, país de nascimento, país de nascimento dos progenitores, determinação dos países com que se estabelece contacto, a diversos níveis: ter familiares estrangeiros, amigos estrangeiros, contactar habitualmente com estrangeiros, ter visitado países estrangeiros e ter residido no estrangeiro. Este primeiro conjunto de itens incluía, ainda, um item que visava medir o contacto, em que os participantes deveriam indicar o número de estrangeiros com quem já tinham falado.

\footnotetext{
${ }^{6} \mathrm{Na}$ investigação original, a variável exogrupo de comparação tinha quatro níveis, incluindo, para além dos três referidos, o nível "sem exogrupo de comparação". Por uma questão de simplificação da exposição, apenas consideramos três níveis.

${ }^{7}$ A referida ambivalência tinha sido encontrada num estudo sobre os estereótipos que os Portugueses desenvolvem de diversos grupos, entre os quais se encontravam os Espanhóis. Para mais pormenores, ver Miranda, J. (1994). Os estereótipos que os "Portugueses" desenvolvem de diferentes grupos étnicos residentes em Portugal. Lisboa: Universidade Aberta (Dissertação de Mestrado). Existe todo um conjunto de literatura que pode ser consultada no trabalho original que fundamenta essa mesma ambivalência.
} 
O segundo bloco de itens (portugueses) incluía diversas questões relativas aos portugueses: grau de importância da pertença nacional, grau de importância de diferentes dimensões identitárias, valorização do endogrupo, importância das diferentes categorias de pertença.

No terceiro bloco de itens (estrangeiros), os itens referiam-se aos estrangeiros residentes em Portugal, em geral: atitudes face aos estrangeiros e estimativa do número de estrangeiros residentes em Portugal. Finalmente, o quarto bloco de itens - espanhóis / americanos / cabo-verdianos (consoante os questionários) - envolvia questões relativas aos espanhóis (questionário 1), aos americanos (questionário 2) e aos cabo-verdianos (questionário 3). $\mathrm{O}$ questionário 4 (versão-controlo) incluía mais questões (do que as presentes nos questionários 1, 2 e 3 ) relativas ao grupo dos portugueses, não requerendo o pronunciar-se relativamente a qualquer exogrupo em particular. Este bloco visava recolher informação relativa à distância social, posicionamento dos exogrupos em relação aos portugueses, em termos de inferioridade/superioridade, estereótipos, grau de atracção pelos exogrupos, predisposição para a mudança atitudinal, número de elementos dos exogrupos com quem se falou, grau de diferença/semelhança dos exogrupos em relação aos portugueses, diferença/semelhança do exogrupo em relação aos portugueses, a nível de diferentes dimensões, grau de atracção do exogrupo pelos portugueses e grau de informação sobre o exogrupo. Os dois últimos itens do questionário não se integravam em nenhum dos conjuntos de itens referidos e procuravam determinar o grau em que os participantes se consideravam racistas e o grau em que consideravam a sociedade portuguesa racista. Analisemos agora, em maior detalhe, os itens que nos interessam neste artigo.

\section{Itens relativos à distância social}

Os itens 58 a 67, que integravam o IV grupo de itens, visavam averiguar o grau de dificuldade dos participantes em desenvolver diversos comportamentos face aos elementos dos diferentes exogrupos (espanhóis, americanos ou cabo-verdianos, consoante o questionário em causa) ou em fazer

face a determinadas situações envolvendo elementos dos exogrupos (por exemplo, "Ter colegas...", "Ter amigos...", "Casar com...") 8 e foram elabo-

\footnotetext{
${ }^{8}$ O bloco IV - espanhóis/americanos/cabo-verdianos - procurou avaliar a variável distância social, mediante um conjunto de dez itens e recorrendo a uma escala de 7 pontos, entre 1, "Falso", e 7, "Verdadeiro". Os itens eram os seguintes: item 58: "Sentar-se ao lado de um/a [...] no autocarro", item 59: "Dançar com um/a [...]", item 60: "Namorar

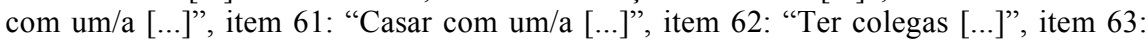
"Que os meus filhos tivessem colegas [...]", item 64: "Empregar um/a [...] na minha
} 
rados tendo por referência a escala de distância social de Bogardus ${ }^{9}$. Através destes itens, pretendeu-se hierarquizar diversos comportamentos/situações sociais, de acordo com o seu grau de dificuldade, e analisar diferenças entre exogrupos, a este nível.

Itens relativos aos estereótipos dos exogrupos e dos endogrupos

Nos itens 69 a 73, de entre os oitenta adjectivos da lista que lhes era fornecida ${ }^{10}$, os participantes deveriam seleccionar os cinco que consideravam melhor caracterizar o exogrupo (espanhóis, americanos ou cabo-verdianos, consoante o questionário em causa), colocar um sinal + ou - à frente de cada adjectivo, consoante considerassem que o adjectivo estava a valorizar ou a desvalorizar o grupo e indicar a percentagem de elementos do exogrupo a que consideravam poder ser atribuído cada um dos adjectivos. Procurou-se, nomeadamente, determinar os estereótipos dos diferentes grupos, bem como o grau de consistência dos mesmos.

Itens relativos à predisposição para a mudança atitudinal

Os itens 75 a 77 pretendiam determinar (numa escala de 7 pontos, entre 1, "Falso", e 7, "Verdadeiro") se os participantes consideravam que a sua atitude face ao exogrupo era ou não passível de alteração e, em caso afirmativo, em resultado de que factores: existirem mais elementos do exogrupo em Portugal (I, 75), terem mais informação sobre o exogrupo (I, 76) ou terem uma relação afectiva com um membro de exogrupo (I, 77). Com base nas respostas a estes três itens, calculou-se o "índice de mudança atitudinal" (I.M.A.).

\section{Procedimento}

A recolha de dados definitivos decorreu com normalidade, durante os meses de Maio e Junho de 1998. Os inquiridos foram abordados na sala de

empresa", item 65: "Que os meus filhos casassem com [...]", item 66: "Ter amigos [...]" e item 67: "Ter chefes [...]".

${ }^{9}$ Estes itens apenas vagamente se basearam em alguns dos itens da escala de distância social elaborada por Bogardus, não visando, de forma alguma, reproduzir a escala original. Sobre a escala em causa, consultar, por exemplo, Alexandre (1971). Les échelles d'attitude. Paris: Éditions Universitaires.

10 Lista utilizada em Miranda, J. (1994). Os estereótipos que os "Portugueses" desenvolvem de diferentes grupos étnicos residentes em Portugal. Lisboa, Universidade Aberta (Dissertação de Mestrado). 
aula, no momento acordado com os respectivos docentes para a cedência de uma hora lectiva. Os objectivos foram apresentados de uma forma geral e suficientemente vaga. De forma a recolher um número semelhante dos diferentes questionários, os questionários foram sendo distribuídos em cada turma seguindo a ordem 1A, 1B, 2A, 2B, 3A, 3B e 4. Trinta questionários estavam incompletos ou incorrectamente preenchidos e foram, portanto, eliminados.

Quadro 2 - Medida de proximidade social (médias e desvios-padrão)

\begin{tabular}{|c|c|c|c|c|c|c|c|c|c|}
\hline \multirow{3}{*}{$\begin{array}{l}\text { Itens } \\
\text { Não teria qualquer } \\
\text { problema em... }\end{array}$} & \multicolumn{6}{|c|}{ Exogrupo de comparação } & \multirow{2}{*}{\multicolumn{2}{|c|}{ Total }} & \multirow{3}{*}{$\begin{array}{c}\text { Estatística } \\
\text { teste }\end{array}$} \\
\hline & \multicolumn{2}{|c|}{ Espanhóis } & \multicolumn{2}{|c|}{ Americanos } & \multicolumn{2}{|c|}{$\begin{array}{c}\text { Cabo- } \\
\text {-Verdianos }\end{array}$} & & & \\
\hline & $M$ & $S D$ & $M$ & $S D$ & $M$ & $S D$ & $M$ & $S D$ & \\
\hline $\begin{array}{l}\text { 58: "Sentar-me ao } \\
\text { lado de um }[. . .] \text { no } \\
\text { autocarro". }\end{array}$ & $6,42 \mathbf{a}$ & 1,43 & $6,57 \mathbf{a}$ & 1,37 & $6,50 \mathbf{a}$ & 1,24 & 6,50 & 1,35 & $\begin{array}{c}F(2,336)= \\
0,35,0,71\end{array}$ \\
\hline $\begin{array}{l}\text { 59: "Dançar com } \\
\text { um/a [...]". }\end{array}$ & $6,51 \mathbf{a}$ & 1,26 & $6,65 \mathbf{b}$ & 1,10 & $6,15 \mathbf{c}$ & 1,44 & 6,44 & 1,29 & $\begin{array}{c}F(2,336)= \\
4,60,0,01 * *\end{array}$ \\
\hline $\begin{array}{l}\text { 60: "Namorar com } \\
\text { um/a [...]". }\end{array}$ & $6,18 \mathbf{a}$ & 1,59 & $6,44 \mathbf{a}$ & 1,25 & $4,79 \mathbf{b}$ & 2,14 & 5,81 & 1,84 & $\begin{array}{c}F(2,336)= \\
30,68,0,00 *\end{array}$ \\
\hline $\begin{array}{l}\text { 61: "Casar com um/a } \\
{[\ldots] \text { ". }}\end{array}$ & $5,74 \mathbf{a}$ & 1,83 & $5,96 \mathbf{a}$ & 1,71 & $4,28 \mathbf{b}$ & 2,25 & 5,34 & 2,08 & $\begin{array}{c}F(2,336)= \\
29,94,0,00^{*}\end{array}$ \\
\hline $\begin{array}{l}\text { 62: "Ter colegas } \\
{[\ldots] \text { ". }}\end{array}$ & $6,39 \mathbf{a}$ & 1,30 & $6,55 \mathbf{a}$ & 1,22 & $6,51 \mathbf{a}$ & 1,19 & 6,48 & 1,24 & $\begin{array}{c}F(2,336)= \\
0,51,0,60\end{array}$ \\
\hline $\begin{array}{l}\text { 63: "Que os meus } \\
\text { filhos tivessem } \\
\text { colegas }[\ldots] " .\end{array}$ & $6,45 \mathbf{a}$ & 1,26 & $6,55 \mathbf{a}$ & 1,24 & $6,51 \mathbf{a}$ & 1,22 & 6,50 & 1,24 & $\begin{array}{l}F(2,336)= \\
0,18,0,84\end{array}$ \\
\hline $\begin{array}{l}\text { 64: "Empregar um/a } \\
\text { [..] na minha } \\
\text { empresa". }\end{array}$ & $5,84 \mathrm{a}$ & 1,79 & 6,27 & 1,43 & $6,39 \mathbf{b}$ & 1,34 & 6,17 & 1,55 & $\begin{array}{c}F(2,336)= \\
3,97,0,01 * *\end{array}$ \\
\hline $\begin{array}{l}\text { 65: "Que os meus } \\
\text { filhos casassem com } \\
{[\ldots] \text { ".. }}\end{array}$ & $5,96 \mathbf{a}$ & 1,62 & $6,10 \mathbf{a}$ & 1,52 & $4,99 \mathbf{b}$ & 2,04 & 5,69 & 1,80 & $\begin{array}{c}F(2,336)=13, \\
65,0,00 * *\end{array}$ \\
\hline $\begin{array}{l}\text { 66: "Ter amigos } \\
{[\ldots] \text { ". }}\end{array}$ & $6,52 \mathbf{a}$ & 1,25 & $6,62 \mathbf{a}$ & 1,14 & $6,51 \mathbf{a}$ & 1,25 & 6,55 & 1,21 & $\begin{array}{c}F(2,336)= \\
0,25,0,77\end{array}$ \\
\hline 67: "Ter chefes $[\ldots]$ ". & $5,20 \mathbf{a}$ & 2,08 & $5,48 \mathbf{a}$ & 1,97 & $5,75 \mathbf{a}$ & 1,93 & 5,48 & 2,00 & $\begin{array}{l}F(2,336)= \\
2,09,0,13\end{array}$ \\
\hline $\begin{array}{l}\text { Índice de proximida- } \\
\text { de social }\end{array}$ & 6,12 & 1,24 & $6,32 \mathbf{a}$ & 1,14 & $5,84 \mathbf{b}$ & 1,21 & 6,10 & 1,21 & $\begin{array}{l}F(2,336)= \\
4,64,0,01^{*}\end{array}$ \\
\hline Alphas de Cronbach & 0,9 & & 0,9 & & 0,9 & & & & \\
\hline
\end{tabular}




\section{Resultados}

Os dados foram analisados através do SPSS (Statistical Package for Social Sciences) para Windows (versão 6.0).

\section{Proximidade social em relação aos exogrupos}

Como pode ser observado no quadro 2 , os comportamentos que os participantes teriam mais dificuldade em aceitar em relação aos espanhóis eram o casamento de filhos seus com espanhóis, casarem eles próprios com espanhóis e, principalmente, terem chefes espanhóis, sucedendo precisamente o mesmo em relação aos americanos. Em relação aos cabo-verdianos, os comportamentos mais difíceis eram os seus filhos casarem com cabo-verdianos, namorar com cabo-verdianos e, essencialmente, casar com cabo-verdianos. Não se encontraram diferenças significativas na predisposição em desenvolver os seguintes comportamentos em relação aos grupos: sentar-se ao lado no autocarro, ter colegas, os filhos terem colegas, ter amigos e ter chefes. Em relação a dançar, encontrou-se maior predisposição para dançar com americanos do que com cabo-verdianos. Em relação a namorar, casar e que os filhos casassem, a predisposição era maior em relação a espanhóis e americanos do que a cabo-verdianos. Finalmente, em relação a empregar na empresa, preferia-se empregar cabo-verdianos a espanhóis.

Encontraram-se diferenças entre exogrupos de comparação $(F(2,327)$ $=4,84, p \leq 0,01)$. De acordo com o teste de Tukey-HSD, os participantes tendiam a considerar que os americanos $(6,32)$ estavam mais próximos dos portugueses do que os cabo-verdianos $(5,84)$. A $2 .^{\mathrm{a}}$ análise confirmou as diferenças entre exogrupos de comparação $(F(2,315)=4,84, p \leq 0,01)^{11}$.

11 No estudo, foram realizadas duas análises de variância, pelo facto de a variável independente ordem de apresentação só existir em três dos quatro questionários do estudo. Assim, na primeira análise, foram consideradas as variáveis sexo, grau de ensino e exogrupo de comparação (consideraram-se, neste caso, todos os sete tipos de questionários). Na segunda análise foram consideradas as variáveis sexo, grau de ensino, exogrupo de comparação e ordem de apresentação (neste caso, o questionário 4 não foi incluído, dado esse questionário não envolver duas ordens de apresentação). 


\section{Estereótipos dos exogrupos e do endogrupo}

Quadro 3 - Os 10 adjectivos mais atribuídos aos grupos e percentagem dos participantes que os selecciona

\begin{tabular}{llll}
\hline Portugueses & Espanhóis & Americanos & Cabo-Verdianos \\
\hline Hospitaleiros (43) & Divertidos (32) & Patriotas (37) & Explorados (40) \\
Tradicionalistas (38) & Patriotas (28) & Negociantes (25) & Pobres (35) \\
Divertidos (30) & Comunicativos (27) & Ambiciosos (24) & Racistas (31) \\
Racistas (26) & Orgulhosos (27) & Racistas (24) & Desconfiados (27) \\
Comunicativos (22) & Barulhentos (25) & Divertidos (23) & Divertidos (24) \\
Críticos (18) & Fanáticos (23) & Comunicativos (21) & Comunicativos (22) \\
Desconfiados (17) & Desconfiados (21) & Poderosos (21) & Marginalizados (20) \\
Preguiçosos (17) & Negociantes (21) & Fanáticos (19) & Barulhentos (20) \\
Prestáveis (17) & Aldrabões (18) & Orgulhosos (19) & Desprotegidos (20) \\
Religiosos (16) & Críticos (17) & Materialistas (18) & Violentos (17) \\
& Religiosos (17) & & \\
\hline
\end{tabular}

Nota: Em relação ao exogrupo dos Espanhóis, são apresentados 11 e não 10 adjectivos, dado que existem dois adjectivos que foram seleccionados por igual percentagem de sujeitos.

Encontrou-se uma tendência para um maior consenso na atribuição de adjectivos aos portugueses e aos cabo-verdianos do que aos americanos e aos espanhóis. Uma vez que cada participante deveria atribuir 5 adjectivos a um dado grupo, dispúnhamos de um total de 2230 adjectivos atribuídos. Desse total, como se pode verificar no quadro 3, 155 adjectivos foram atribuídos, considerando que, entre 0 a $20 \%$ dos membros do grupo, o possuíam, 198 considerando que 21 a $40 \%$ dos membros o possuíam, 516 considerando 41 a $60 \%$ dos membros, 483 considerando 61 a $80 \%$ dos membros e apenas 483 considerando 81 a $100 \%$ dos membros. Os dez adjectivos mais atribuídos aos grupos e a percentagem de participantes que os selecciona pode ser analisada no quadro 4 .

Quadro 4- Estimativas relativas à percentagem de elementos dos exogrupos que possuem cada adjectivo

\begin{tabular}{lcc}
\hline Categorias & $\boldsymbol{N}$ & $\boldsymbol{\%}$ \\
\hline $\mathbf{1}-0-20 \%$ & 155 & 6,95 \\
$\mathbf{2}-21-40 \%$ & 198 & 8,88 \\
$\mathbf{3}-41-60 \%$ & 516 & 23,14 \\
$\mathbf{4}-61-80 \%$ & 878 & 39,37 \\
$\mathbf{5}-81-100 \%$ & 483 & 21,66 \\
Total & 2230 & 100 \\
\hline
\end{tabular}




\section{Avaliação dos atributos}

Apesar de a grande maioria dos 80 adjectivos apresentar um sentido positivo ou negativo mais ou menos unívoco, tal não sucedeu em relação a alguns adjectivos. Apenas a título exemplificativo, referimos os adjectivos "explorados" e "orgulhosos". Em relação a "explorados", dos 45 participantes que o utilizaram para caracterizar um grupo, 26 consideraram que o adjectivo menosprezava o grupo. Pelo contrário, 19 participantes utilizaram o adjectivo para valorizar o grupo. Em relação ao adjectivo "orgulhosos", verificou-se a mesma ambivalência. Dos 72 participantes que o atribuíam a um grupo, 26 participantes utilizaram o adjectivo para desvalorizar o grupo e 46 participantes para o valorizar.

\section{Predisposição para a mudança atitudinal}

Como pode ser constatado no quadro 5, ter uma relação afectiva com um(a) Espanhol(a) é o factor que os participantes consideraram que mais poderia contribuir para que passassem a gostar mais de espanhóis, seguido de ter mais informação sobre Espanha e, por último, de existirem mais espanhóis em Portugal. Em relação aos Estados Unidos, sucedeu o mesmo. Assim, ter uma relação afectiva com um(a) Americano(a) foi o factor que os participantes consideraram que mais poderia contribuir para que passassem a gostar mais de americanos, seguido de ter mais informação sobre os Estados Unidos e de existirem mais americanos em Portugal. Relativamente a Cabo Verde, os participantes consideraram que o factor que mais poderia contribuir para que passassem a gostar mais de cabo-verdianos seria ter mais informação sobre Cabo Verde, seguido de ter uma relação afectiva com um(a) cabo-verdiano(a) e de existirem mais cabo-verdianos em Portugal.

Analisando item a item, considerou-se que existirem mais elementos do exogrupo em Portugal poderia contribuir mais para uma mudança atitudinal em relação a Espanha do que em relação a Cabo Verde. Por outro lado, ter uma relação afectiva com um elemento do exogrupo revelou-se um factor mais determinante da mudança atitudinal em relação a Espanha e aos Estados Unidos, do que a Cabo Verde.

Tendo em consideração o conjunto dos três exogrupos, ter uma relação afectiva com um elemento do exogrupo foi considerado mais determinante de uma mudança atitudinal e existirem mais elementos do exogrupo em Portugal o menos relevante. De resto, a tendência foi para considerar que este factor não contribuiria para se passar a gostar mais daqueles grupos e que teria um efeito precisamente inverso. 
Quadro 5 - Itens 75 a 77 e índices de mudança atitudinal (médias e desvios-padrão)

\begin{tabular}{|c|c|c|c|c|c|c|c|c|c|}
\hline \multirow[b]{2}{*}{ Itens } & \multicolumn{2}{|c|}{ Espanha } & \multicolumn{2}{|c|}{$\begin{array}{l}\text { Estados } \\
\text { Unidos } \\
\end{array}$} & \multicolumn{2}{|c|}{ Cabo Verde } & \multicolumn{2}{|c|}{ Total } & \multirow{2}{*}{$\begin{array}{l}\text { Estatística } \\
\text { teste }\end{array}$} \\
\hline & $M$ & $S D$ & $M$ & $S D$ & $M$ & $S D$ & $M$ & $S D$ & \\
\hline $\begin{array}{l}\text { 75: Existirem elemen- } \\
\text { tos do exogrupo em } \\
\text { Portugal }\end{array}$ & $2,81 \mathbf{a}$ & 1,67 & 3,68 & 1,74 & $2,77 \mathbf{b}$ & 1,68 & 3,09 & 1,75 & $\begin{array}{c}F(2,336)= \\
10,40,0,00^{* *}\end{array}$ \\
\hline $\begin{array}{l}\text { 76: Ter mais informa- } \\
\text { ção sobre o exogrupo }\end{array}$ & 4,57 & 1,84 & 4,41 & 1,80 & 4,97 & 1,80 & 4,65 & 1,82 & $\begin{array}{c}F(2,336)= \\
2,90,0,06\end{array}$ \\
\hline $\begin{array}{l}\text { 77: Ter uma relação } \\
\text { afectiva com um ele- } \\
\text { mento do exogrupo }\end{array}$ & 5,02 & 1,70 & 4,94 & 1,98 & 4,25 & 2,00 & 4,74 & 1,82 & $\begin{array}{l}F(2,336)= \\
5,50,0,00^{* *}\end{array}$ \\
\hline $\begin{array}{l}\text { Índices de mudança } \\
\text { atitudinal }\end{array}$ & 4,13 & 1,25 & 4,34 & 1,50 & 4,00 & 1,44 & 4,16 & 1,40 & $\begin{array}{c}F(2,336)= \\
1,74,0,18\end{array}$ \\
\hline Alphas de Cronbach & 0,5 & & & & & & & & \\
\hline
\end{tabular}

$* p<0,05 ; \quad * * p<0,01$

Nota: O índice de mudança atitudinal para cada exogrupo é calculado com base na soma das respostas aos itens 75-77 e posterior divisão por três.

\section{Discussão}

No que diz respeito aos comportamentos que os participantes teriam mais ou menos dificuldades em desenvolver relativamente ao conjunto dos três grupos considerados ou, de outra forma, à distância social, os três comportamentos em relação aos quais existem mais problemas são (por ordem crescente de dificuldade): "Que os meus filhos casassem com [...]", "Ter chefes [...]" e "Casar com um/a [...]". Existem, pois, reticências em desenvolver comportamentos que envolvam uma relação "permanente", próxima ou íntima, do próprio ou de um seu descendente, com alguém do outro grupo (materializada numa situação de casamento) e em depender hierarquicamente de alguém do outro grupo, de ter um chefe, de aceitar ordens. Esta última situação revelou-se particularmente difícil, dado ter subjacente e implícita uma relação de desigualdade, de subordinação funcional, na qual a inferioridade em relação ao exogrupo pode estar mais ou menos implícita. Para além deste aspecto, as situações que envolvem intimidade, como o casamento, são particularmente problemáticas quando se trata de cabo-verdianos. Note-se que os cabo-verdianos são o grupo em relação ao qual este tipo de comportamentos é mais difícil e aquele em relação ao qual a distância social é maior. Mas os cabo-verdianos deixam de constituir pro- 
blema quando se trata, por exemplo, de os ter como empregados, o que é, de resto, um resultado adaptado à sua condição objectiva de executores dos trabalhos pesados que os nacionais rejeitam, recebendo, em troca, salários baixos. De facto, enquanto empregados, os cabo-verdianos foram claramente preferidos aos espanhóis e aos americanos. Esta parte do questionário revelou-se particularmente feliz, ao permitir desvendar esse preconceito em relação aos cabo-verdianos, preconceito esse que conseguiu permanecer perfeitamente camuflado nas respostas a outros itens de carácter mais geral e em que o conformismo a certas normas de desejabilidade social parece desempenhar um papel fundamental. De ressalvar, ainda, que a população do estudo inclui um número significativo de participantes que nasceram nos PALOP e/ou cujos progenitores também e que, assim sendo, o preconceito em relação aos cabo-verdianos poderá ser menor do que numa população em que tal não se verifique.

Os americanos são considerados mais próximos do que os cabo-verdianos, mas não existem diferenças significativas em termos de proximidade entre americanos e espanhóis nem entre espanhóis e cabo-verdianos.

Encontra-se uma contradição entre níveis de medida quando, por exemplo, a tendência das respostas vai no sentido de não se considerarem os cabo-verdianos significativamente inferiores aos portugueses ${ }^{12}$ e quando, entre outras coisas, se teria problemas em dançar, namorar ou casar com eles. Poder-se-á perguntar: Se não são inferiores, então qual é o problema? Neste aspecto, como noutros ao longo do questionário, uma certa racionalidade, uma preocupação com o ser racional e demonstrar justiça parece estar subjacente às respostas. Esta preocupação com a demonstração de justiça pode ser considerada equivalente à estratégia "justiça" (fairness) a que Tajfel se refere em relação aos estudos de grupo mínimo (por exemplo, Tajfel, 1978). Este resultado salienta a dicotomia entre racismo subtil e flagrante, amplamente discutida por Vala (1999) e por Vala et al. (1999).

Uma significativa consistência a nível dos estereótipos foi encontrada. Os participantes detinham imagens claras dos grupos em causa. Podemos dizer que existia uma imagem mais ou menos consensual sobre como são os portugueses, os espanhóis, os americanos e os cabo-verdianos. Apesar de tudo, há que ter presente que, quando se atribui um dado adjectivo a um grupo, se pode estar a considerar que apenas uma dada percentagem dos participantes desse grupo possui esse adjectivo ou, pelo menos, que a maioria dos membros é passível de ser caracterizada por esse adjectivo, mas não todos os membros do grupo. Este aspecto não pode ser

12 Este resultado refere-se a um item não desenvolvido neste artigo. 
negligenciado no estudo dos estereótipos. De resto, o próprio julgamento de um adjectivo como positivo ou negativo pode revelar-se extremamente subjectivo. Tratando-se de uma população de jovens, esta questão assume uma particular pertinência, dado que, no âmbito de uma cultura juvenil, cujos valores, frequentemente, se afirmam pela diferença em relação às ideias e concepções da sociedade "adulta" mais convencional, ser "sujo", "barulhento", "fanático" ou "preguiçoso" pode representar algo desejável, enquanto que ser "ambicioso" ou "poderoso" pode significar algo indesejável.

Do conjunto dos três factores de mudança atitudinal apresentados, o factor ter uma relação afectiva com um elemento do exogrupo foi o considerado como sendo mais determinante de uma mudança atitudinal. Pelo contrário, existirem mais elementos do exogrupo em Portugal foi o factor considerado menos determinante. A tendência é, de facto, para considerar que a existência de mais elementos do exogrupo em Portugal contribuiria para desenvolver uma atitude mais negativa.

Analisando exogrupo a exogrupo, é curioso constatar que, quer em relação a Espanha, quer em relação aos Estados Unidos, o factor ter uma relação afectiva com um elemento do exogrupo foi, dos três considerados, o mais relevante para a mudança. No entanto, em relação aos cabo-verdianos, o factor mais relevante foi ter mais informação sobre o exogrupo. Este resultado tem implícita a reserva que se coloca em relação a vir a desenvolver uma relação afectiva com um cabo-verdiano e vem reforçar o preconceito em relação aos cabo-verdianos já referido. No conjunto dos factores, não existe nenhum que os participantes considerassem que pudesse, indiscutivelmente, contribuir para uma mudança atitudinal, o que é concordante com a ideia de que atitudes e estereótipos são difíceis de alterar. Mesmo que a mudança ocorra num indivíduo, em resultado de um dado factor ou experiência pessoal, dificilmente a mudança se repercutirá ao grupo, no seu conjunto.

A hipótese geral desta investigação foi confirmada. Assim, verificámos que a identidade social não é uma criação do próprio grupo, antes se inscreve numa dinâmica intergrupal (na relação entre os portugueses e os outros grupos), de ordem psicossociológica. O ser Português é, pois, um processo de construção, desempenhando os demais alvos de comparação um papel determinante na construção da identidade nacional. A identidade nacional foi confrontada com outras que evocaram relações intergrupais de assimetria variada, tendo os portugueses sido dominantes nuns contextos e dominados noutros, dado cada grupo ocupar um lugar simbólico na memória colectiva dos portugueses. 
Assim, na nossa perpectiva, um dado grupo nacional não apresenta um dado estatuto social, mas, antes, diversos estatutos transitórios, passíveis de contínua modificação, de passagem de dominante para dominado e vice-versa. Para a compreensão da referida mobilidade de estatutos e de auto-representações, os três níveis de análise (social, psicológico e ideológico) descritos por Doise, deverão ser sempre considerados em simultâneo, podendo a negligência de qualquer um dos mesmos perturbar toda a análise.

$\mathrm{Na}$ sequência da hipótese da assimetria da Escola de Genève e do conceito de "assimetria simbólica" de Amâncio (1993), consideramos relevante introduzir o conceito de assimetria variada nas relações intergrupais, que pretende traduzir a ideia de que o mesmo grupo pode assumir uma posição de dominante, num dado contexto de comparação, e a de dominado, num outro contexto.

Codol salientou, nos seus diversos estudos, que identidade e representações sociais estão largamente dependentes das ideologias e dos contextos de comparação ou, mais especificamente, das normas do contexto. No nosso estudo, as normas do contexto de comparação são o próprio desenho experimental, envolvendo a saliência da comparabilidade.

A hipótese 1 partiu do pressuposto de que, se os americanos constituem um grupo de referência positiva e os cabo-verdianos um grupo de referência negativa, a diferenciação em relação aos cabo-verdianos deve ser maior do que a diferenciação em relação aos americanos, sendo que os espanhóis poderão ocupar uma posição intermédia. Esta hipótese é, pelo menos, parcialmente confirmada, sendo os americanos considerados mais próximos do que os cabo-verdianos.

Em geral, os estudos no âmbito da teoria da identidade social, tal como a grande maioria dos estudos do comportamento intergrupal, apenas consideram dois grupos de comparação e terceiros grupos apenas surgem no background teórico enquanto alternativas de comparação extremamente vagas. Assim sendo, na nossa perspectiva, esta investigação encontra-se mais próxima do mundo social real, no qual cada grupo é, frequentemente, confrontado com mais do que um grupo em simultâneo.

\section{Referências}

Amâncio, L. (1993a). Género - representações e identidades. Sociologia - Problemas e Práticas, 14, 127-140.

Amâncio, L. (1994). Masculino e feminino. A construção social da diferença. Porto: Edições Afrontamento.

Amâncio, L. (1997). The importance of being male: ideology and context in gender identities. Revue Internationale de Psychologie Sociale, 2, 79-94. 
Augoustinos, M. \& Walker, I. (1995). Social cognition. An integrated introduction. Londres/California/Nova Deli: Sage.

Billig, M. (1993). Studying the thinking society: social representations, rhetoric, and attitudes. In G. M. Breakwell \& D. V. Canter (Eds.), Empirical approaches to social representations (pp. 39-62). Oxford: Clarendon Press.

Breakwell, G. M., \& Cantor, D. V. (1993) (Eds.). Empirical approaches to social representations. Oxford: Clarendon Press.

Codol, J. P. (1984). Social differentiation and non-differentiation. In H. Tajfel (Ed.), The social dimension (Vol. 1, pp. 314-337). Cambridge: Cambridge University Press.

Deschamps, J. C. (1982a). Différentations entre soi et autri et entre groupes. In J. Ph. Leyens (Ed.), Cognitive analysis of social behavior (pp. 247-266). Holanda: Martinus Nijhoff Publishers/The Hague.

Deschamps, J. C. (1982b). Social identity and relations of power between groups. In H. Tajfel (Org.), Social identity and intergroup relations. Londres/Paris: Cambridge University Press/Maison des Sciences de l'Homme.

Doise, W. (1976). A articulação psicossociológica e as relações entre os grupos. Lisboa: Moraes Editores.

Doise, W. (1982). L'explication en psychologie sociale. Paris: P.U.F.

Doise, W. (1987). Le social et l'individuel: théories générales et recherches intergroupes. Psychologie et Éducation, 11, 57-74.

Doise, W. (1984). Social representations, intergroup experiments and levels of analysis. In R. M. Farr \& S. Moscovici (Orgs.), Social representations. Londres/Paris: Cambridge University Press/Maison des Sciences de l'Homme.

Eurobaromètre standard. (1997), 48.

Lorenzi-Cioldi, F. (1988). Individus dominants et groupes dominés. Images masculins et féminines. Grenoble: Presses Universitaires.

Malewska-Peyre, H. (1990). Le processus de dévalorisation de l'identité et les stratégies identitaires. In C. Camilleri, J. Kastersztein, E. M. Lipiansky, H. Malewska-Peyre, I. Taboada-Leonetti \& A. Vasquez. Stratégies identitaires (pp. 111-141). Paris: Presses Universitaires de France.

Miranda, J. (2002). Identidade nacional. Do mito ao sentido estratégico. Uma análise psicossociológica das comparações entre os Portugueses e os Outros. Oeiras: Celta.

Santos, B.S. (1994). Pela mão de Alice. O social e o político na pós-modernidade. Porto: Edições Afrontamento.

Taboada-Leonetti, I. (1990). Stratégies identitaires et minorités: le point de vue du sociologue. In C. Camilleri, J. Kastersztein, E. M. Lipiansky, H. MalewskaPeyre, I. Taboada-Leonetti \& A. Vasquez. Stratégies identitaires (pp. 43-83). Paris: Presses Universitaires de France.

Tajfel, H. (Ed.). (1978). Differentiation between social groups. Studies in the social psychology of intergroup relations. Londres: Academic Press.

Telo, A. J. (1997). Treze teses sobre a disfunção nacional - Portugal no sistema internacional. Análise Social, 32 (142), 649-683. 
Turner, J. C. (1985). Social categorization and the self-concept: a social cognitive theory of group behavior. In E. J. Lawlwe (Éd.), Advances in group processes (Vol. 2, pp. 77-121). Greenwich, CP: JAI Press.

Turner, J. C., Hogg, M. A., Oakes, P. J., Reicher, S. D., \&, Wetherell, M. (1987). Rediscovering the social group: a self-categorization theory. Oxford: Blackwell.

Turner, J. C. \& Oakes, P. J. (1989). Self-categorization theory and social influence. In P. B. Paulus (Éd.), Psychology of group influence (2. ${ }^{\mathrm{a}}$ ed.). Hillsdale, Nova Jérsia: Erlbaum.

Vala, J. (Org.). (1999). Novos racismos. Perspectivas comparativas. Oeiras: Celta.

Vala, J., Brito, R., \& Lopes, D. (1999). Expressões dos racismos em Portugal. Lisboa: Instituto de Ciências Sociais. 